\title{
Experiences of Community Violence Among Adults with Chronic Conditions: Qualitative Findings from Chicago
}

\author{
Elizabeth L. Tung, MD, $M S^{1,2,3}$, Tyrone A. Johnson, $B S^{1,3}$, Yolanda O'Neal, MPA', \\ Althera M. Steenes, $B A^{7}$, Graciela Caraballo, $B S^{7}$, and Monica E. Peek, MD, MPH, MS ${ }^{1,3}$ \\ 'Section of General Internal Medicine, Department of Medicine, Chicago Center for Diabetes Translation Research, University of Chicago, \\ Chicago, IL, USA; ${ }^{2}$ The Center for Health and the Social Sciences, University of Chicago, Chicago, IL, USA; ${ }^{3}$ Pritzker School of Medicine, University of \\ Chicago, Chicago, IL, USA.
}

BACKGROUND: Community violence is an important social determinant of health in many high-poverty, urban communities.

OBJECTIVE: The purpose of this study was to explore and characterize self-described experiences of community violence among adults with chronic health conditions. DESIGN: Qualitative study design was implemented in 2017 using in-depth, semi-structured focus groups and interviews; data were collected from two clinical sites located in geographic epicenters of high violent crime in Chicago.

PARTICIPANTS: Adult patients, ages 35 years and older, who had at least one chronic condition.

APPROACH: Data were analyzed using grounded theory and the constant comparison method.

KEY RESULTS: The overall sample $(N=51)$ was predominantly female (67\%) and black non-Hispanic (75\%); a large proportion had hypertension (65\%), arthritis (55\%), obesity (53\%), and/or diabetes (45\%). The majority reported that a close friend or family member was seriously injured or killed due to community violence (71\%); a similar proportion had never discussed their experiences of community violence with a healthcare provider (73\%). Several major themes emerged: (1) perceived risk of being targeted, (2) chronic stress and worry, (3) hypervigilance, (4) social breakdown, (5) chronic isolation, (6) constrained choice (loss of freedom), (7) limited access to material resources, and (8) inadequate healthcare responses.

CONCLUSIONS: Patients often struggled to balance the challenges imposed by community violence with the demands of living with and managing their chronic conditions. Emergent themes may inform practical targets for addressing community violence as a social determinant of health in vulnerable populations.

KEY WORDS: community violence; neighborhood crime; chronic disease; health disparities; obesity; hypertension; social risk factors.

Electronic supplementary material The online version of this article (https://doi.org/10.1007/s11606-018-4607-3) contains supplementary material, which is available to authorized users.

Received February 4, 2018

Revised June 6, 2018

Accepted July 10, 2018

Published online August 3, 2018
J Gen Intern Med 33(11): 1913-20

DOI: $10.1007 / \mathrm{s} 11606-018-4607-3$

(C) Society of General Internal Medicine 2018

\section{INTRODUCTION}

Community violence is an enduring public health challenge in many high-poverty, urban communities. Violent death can have rippling effects on a victim's family, friends, and surrounding community; and for each violent death, there are 120 additional violent crimes (e.g., robbery, assault, police brutality) that can have compounding consequences. ${ }^{1,2} \mathrm{~A}$ recent study in Chicago documented that among black adolescents living in a highcrime region, almost half had witnessed someone killed and $85 \%$ reported a serious death or injury of someone close. ${ }^{3}$ In another Chicago study, $42 \%$ of community-dwelling adults screened positive for PTSD in a high-poverty outpatient clinic. ${ }^{4}$

Given this pervasive exposure to violent crime, there has been growing recognition of community violence as a social determinant of health in vulnerable populations. Persistent exposure to community violence has been associated with deleterious health effects, not only for mental health but also for physical health. ${ }^{5-7}$ For instance, one prior study examined 9252 US adults and found that higher crime rates were associated with higher BMI. ${ }^{8}$ Sundquist and colleagues followed nearly 700,000 adults in Sweden and found that when neighborhood violent crime and unemployment increased, the risk of heart disease increased for both men and women. ${ }^{9}$ These studies point to a consistent relationship between violent crime and chronic disease in adult populations.

Studies examining the mechanisms of this linkage to chronic disease have emphasized the impact of violence on personal health behaviors (e.g., lack of physical activity) ${ }^{10,11}$ and stress response pathways (e.g., allostatic load). ${ }^{12,13}$ For instance, numerous studies have documented a relationship between community violence, green space, and reduced physical activity. ${ }^{14,15}$ Billimek and colleagues also demonstrated that patients who reported living in unsafe neighborhoods had greater difficulties with treatment adherence, including delays in filling prescription medications. ${ }^{11}$ Other work has described a relationship between community violence and poor social cohe- 
sion, ${ }^{16,17}$ with implications for aging populations who often rely on friends or family members for health-related activities.

Despite this body of work, few studies have examined how patients themselves make sense of community violence and the multiplicity of factors that might work together to drive complex health outcomes. We did not find any qualitative studies that focused on adults with chronic conditions who live in high-crime neighborhoods and must manage their illnesses within this type of adverse environment. This population may be particularly insightful for identifying theoretical mechanisms along the pathway from violent crime to chronic disease. In fact, much of the work in this area has tended to focus on children and adolescents ${ }^{14,18}$ or on more general health promotion and wellness. ${ }^{14}$ However, younger or more general patient populations may not necessarily develop chronic disease and are likely to experience violence differently. For instance, an older adult with arthritis and ambulatory challenges, who cannot easily escape or avoid a dangerous situation, may be affected by violence in ways that a young or able-bodied adult may not.

The purpose of this study was to characterize the relationship between community violence and chronic disease in an adult population. We explored the narratives of middleaged and older adult patients living in high-crime neighborhoods to generate hypotheses about the underlying mechanisms that, over time, may contribute to poor health outcomes. We sought to identify the consequences of community violence in this population as potential targets for directing an informed healthcare response. Based on our findings, we developed a theoretical model to illustrate potential pathways.

\section{METHODS}

Between April and October 2017, we conducted eight focus groups and six interviews with adults, ages 35 years and older, who had at least one chronic condition. Participants were purposefully recruited from two primary care clinics in geographic epicenters of high violent crime in Chicago (Online Appendix Fig. 1). Research staff contacted potential participants as a consecutive convenience sample via phone or inperson at two clinical sites. Recruitment was continued until theoretical saturation was achieved. Due to the sensitive nature of interview content, target focus group size was 4 to 6 participants. Each participant received a $\$ 30$ incentive.

Prior to each session, participants completed a brief questionnaire about sociodemographic and neighborhood characteristics, healthcare access, and prior exposure to violence; items were derived from previously validated measures. ${ }^{19-22}$ All focus groups and interviews were conducted by racially concordant interviewers, in English or Spanish, using a semistructured interview guide. Questions were open-ended, followed by probes designed to explore topics more deeply. The interview guide explored topics related to experiences and consequences of community violence and healthcare responses to community violence. The topic guide was modified iteratively to improve the flow and comprehensibility of questions. Focus groups and interviews were 60-90 and 30$60 \mathrm{~min}$ in duration, respectively; all sessions were audio recorded with handheld devices. Field notes were taken by the principal investigator. Data were extracted from audio recordings, transcribed verbatim, and de-identified during the transcription process.

The research team consisted of six reviewers trained in qualitative research, including two physician researchers. All reviewers read and inductively coded the first two transcripts using grounded theory and the constant comparison method. The entire research team participated in development of the initial codebook. For internal consistency, one primary reviewer read and coded all 16 transcripts; the remaining reviewers independently read and coded 3-4 randomly distributed transcripts. The primary reviewer wrote reflexive and theoretical memos throughout the coding process and met with each reviewer to discuss discrepant coding assignments. The remaining discrepancies were resolved by the entire team. The codebook was refined through an iterative process until all team members agreed on the final coding structure and were satisfied with the level of intercoder agreement. Data were triangulated using transcripts, audio files, participant questionnaires, and field notes.

Analyses were conducted using Atlas.ti v.1.0.48 and Stata/ SE v.13.1. This study was approved by the University of Chicago Institutional Review Board.

\section{RESULTS}

\section{Participant Characteristics}

The overall sample included 51 participants, including 27 from an academic medical center and 24 from a federally qualified health center (Online Appendix Fig. 1). The sample was predominantly female (67\%) and identified as black nonHispanic (75\%); a subsample of Spanish-speaking Hispanic/ Latino participants $(20 \%)$ was purposefully recruited (Table 1). Approximately one-third reported an annual household income less than $\$ 25,000$. The majority was insured by Medicaid $(29 \%)$ or Medicare $(24 \%)$ or was dual eligible (14\%); a large proportion had hypertension (65\%), arthritis $(55 \%)$, and/or obesity $(53 \%)$. Many reported being a prior victim of $(43 \%)$ or witness to $(60 \%)$ a violent act; a large proportion (71\%) reported that a close friend or family member was seriously injured or killed due to violence (Table 2). The majority had never discussed their experiences of community violence with a healthcare provider (73\%).

\section{Emergent Themes}

Major themes with featured quotations are provided below; supplementary quotations for all themes can be found in Online Appendix Table 1. 
Table 1 Participant Characteristics, Chicago, IL, 2017

\begin{tabular}{|c|c|}
\hline$N=51$ & $\%$ \\
\hline \multicolumn{2}{|l|}{ Demographic characteristics } \\
\hline \multicolumn{2}{|l|}{ Age (years) } \\
\hline $35-49$ & 21.6 \\
\hline $50-59$ & 29.4 \\
\hline $60-69$ & 39.2 \\
\hline $70+$ & 9.8 \\
\hline \multicolumn{2}{|l|}{ Gender } \\
\hline Female & 66.7 \\
\hline Male & 33.3 \\
\hline \multicolumn{2}{|l|}{ Race/ethnicity } \\
\hline White non-Hispanic & 3.9 \\
\hline Black non-Hispanic & 74.5 \\
\hline Hispanic/Latino & 19.6 \\
\hline Other & 2.0 \\
\hline \multicolumn{2}{|l|}{ Education } \\
\hline Less than high school graduate & 19.6 \\
\hline High school graduate or equivalent & 21.6 \\
\hline Some college or 2 -year college graduate & 33.3 \\
\hline 4-year college graduate & 13.7 \\
\hline More than 4-year college graduate & 11.8 \\
\hline \multicolumn{2}{|l|}{ Annual household income } \\
\hline Less than $\$ 25,000$ & 33.3 \\
\hline$\$ 25,000-\$ 49,000$ & 21.6 \\
\hline$\$ 50,000-\$ 99,000$ & 19.6 \\
\hline$\$ 100,000+$ & 3.9 \\
\hline Not sure or refused & 21.6 \\
\hline \multicolumn{2}{|l|}{ Health and healthcare characteristics } \\
\hline \multicolumn{2}{|l|}{ Insurance status } \\
\hline Employer-based plan & 17.7 \\
\hline Medicaid only & 29.4 \\
\hline Medicare only & 23.6 \\
\hline Medicaid/Medicare dual eligible & 13.7 \\
\hline No insurance & 7.8 \\
\hline Other & 7.8 \\
\hline \multicolumn{2}{|l|}{ Self-reported health status } \\
\hline Poor & 9.8 \\
\hline Fair & 43.1 \\
\hline Good & 41.2 \\
\hline Very good & 5.9 \\
\hline Excellent & 0 \\
\hline \multicolumn{2}{|l|}{ Chronic health conditions } \\
\hline Hypertension & 64.7 \\
\hline Arthritis & 54.9 \\
\hline Obesity & 52.9 \\
\hline Diabetes & 45.1 \\
\hline Depression & 27.5 \\
\hline
\end{tabular}

\section{"If You Look Like a Square:" Risk of Being Targeted.} Participants expressed concern that they were at higher risk for being victims of violent crime. Some attributed risk to the overall ubiquity and prevalence of crime in their neighborhoods:

Violence affects everybody... no one is isolated from the violence in our communities... if it ain't you, it's your neighbor, it's someone that you know. (FG1)

Others attributed risk to older age or poor health status:

I consider myself savvy about what's happening around me, and I will not go into areas where I know that I'm going to be singled out as such. I keep a low profile... I'm a senior, I've got a condition where I need a cane, and I probably look like I could be pushed over pretty easy. (FG2)
I'm 66 and I use public transportation. I worry about my safety, because I ain't as fast as I used to be... if you look like a square or whatever, they'll attack you. They prey on old people. (FG1)

"It Keeps Me Up at Night:" Chronic Stress or Worry. A common theme was persistent exposure to violence, which resulted in chronic stress or worry:

[Violence] affects me a lot because when I see and hear about [shootings], I get really nervous... it's stressful worrying both by day and by night. (FG8)

Many described excessive worry about friends and family members:

Being a grandmother, you worry about your grandkids being out there on the street. My grandson out there, hope don't nobody kill him. That's stressing you out just from him being outside. (FG2)

Participants also described stress as having direct consequences on mental and physical health:

Before, we lived on [a dangerous street]... and every weekend, there would be shootings. You weren't comfortable there, you felt really stressed out... the window in my bedroom faced the house where they were selling drugs... I would feel like my heart wanted to come out of me because my kid was there, we were sleeping there. I even went to the hospital because [it made me] sick. (FG8)

"You Have To Have Your Guard Up:" Hypervigilance. Participants described a state of hypervigilance-heightened awareness of their surroundings - which resulted in scanning the external environment for threats and preparing for potentially violent situations:

I'm aware for my survival, I've got to be conscious of when I go in and when I come out and constantly aware of what's happening... You have to be conscious if you don't want to get robbed. (FG6)

I carry a knife... all I want to do is be able to keep you off me... Even when I go to church on Sunday, I got it on me, because I'm on public transportation... I sit on the bus or the train, reading my newspaper. But I have one hand on the paper, one hand on the knife... to be aware is to be alive. (FG1)

"You Stay Inside:" Chronic Isolation. Participants described chronic isolation, both physical and social, that resulted from violence. People often responded to violence by staying inside their homes, which made self-care activities more difficult: 
Table 2 Participants' Experiences of Community Violence

\begin{tabular}{ll}
\hline \hline $\boldsymbol{N}=\mathbf{5 1}$ & $\mathbf{\%}$ \\
\hline Violence exposure characteristics & \\
$\quad$ Prior victim of community violence (direct) & 43.1 \\
$\quad$ Prior witness to community violence (direct) & 60.4 \\
Close friend or family member was seriously injured or killed & 71.4 \\
$\quad$ (indirect) & 84.3 \\
Any of the above exposures to violence & \\
Stress due to violence & 7.8 \\
$\quad$ Not stressful & 52.9 \\
Somewhat stressful & 21.6 \\
Stressful & 17.7 \\
Very stressful & 23.5 \\
Ever discussed violence with a healthcare provider & 72.6 \\
Yes & 3.9 \\
No & \\
Not sure & \\
\hline
\end{tabular}

That's really what's keeping me inside. I would like to come out, but I stay inside because [violent incidents] be going on... I have arthritis. It affects it because you can't get out to walk on a day to day basis - that would help the arthritis. I stay in the house pretty much. (FG6) If you're scared to go out of the house, you're not going to go get that help that you need. (FG4)

In addition to physical isolation, participants also described social isolation:

I'm scared for my family to come visit because of it. They're like, "You're on the west side, I'm not going to come visit you." I was close to my family... Being condemned to your own house. (FG7)

Some [women] will not go out at night. So if there's an event that they've been invited to from 7 to 9 , most of them won't go. If it's going to be dark when I'm trying to get back home, they're afraid. And that's because of violence. What it does is you become a true homebody, you stay inside. (FG1)

Other times, social isolation was the consequence of people moving away:

[You] think about all the people you used to know that used to live far south that don't live in that area any more... left because of the community violence. (INT3)

“You Want To Help People Less:" Social Breakdown. Many reported a breakdown in social cohesion. For example, the prevalence of violence in their communities created a sense of suspicion and distrust of others:

One day I was working in my yard, I was bending over and a young guy walks up to me. He had his hand in a paper bag. It looked like a gun — but it was a drill he wanted to sell me... you know, it scared me. My heart was pounding so hard I thought I was going to have a heart attack out there... and I don't like to think that way of my people. (FG1)

Others described a presumption of guilt that dissuaded people from helping others in need:

Unfortunately, if they're beating you up, they walk right on by... the other Hispanics think, "He must have done something wrong." (FG8)

Distrust ultimately led to social distancing and breakdown:

It was mentioned, we try to help each other... But we tend to want to do that less these days, because again, crime and violence... because I don't know who you are. And if you walk towards me, I put my hand up - stop, I don't want you within seven feet of me. (FG1)

There are a lot of Hispanics, but we're not united... we don't trust each other, right? (INT2)

\section{"You Have To Have a Plan:" Constrained Choice (Loss of} Freedom). Many people described community violence as a practical constraint on daily choices and activities. Time of day (e.g., night time), mode of transportation (e.g., public bus), and location (e.g., rival gang territory) were commonly cited constraints due to violence:

Your health is affected because you really can't be spontaneous. You've got to have a plan: I'm going to the grocery store at this time; let me go where I'm comfortable; I'll wait for when my daughter or my son is coming; [when I can get] a ride or something. (FG2) We would take [people] grocery shopping... and [the man] said, "Look man, I can't cross over the [highway]... Those are rivals. They will shoot me and they'll shoot anybody in here." He stayed on the east side, and the [grocery store] was on the west side of the [highway]... there is boundary issues. (FG5)

Some described these constraints as not only limiting freedom but also precipitating poorer health choices:

I'm not going to go buy the groceries like mom and pop used to do. I'm going to run to the fast food restaurant... because it's quicker, and you don't have to go past them guys. I try to cook more healthy food. But it's still a tendency to [eat fast food]... because it's easier and quicker to get back home. That's the whole mentality: Be inside. If I'm in my home, I'm safe. (FG1)

"There's Nothing There:" Limited Access to Material Resources. Participants described a relationship between violence in their communities and the quantity of resources available to them: 
Table 3 Healthcare Provider Responses to Community Violence: Quotations by Sub-theme

\begin{tabular}{|c|c|}
\hline Sub-theme & Illustrative quotation \\
\hline Insufficient response & $\begin{array}{l}\text { "My physician has not ever asked me [if community violence affects me], but... I guess he figures there's not reason to ask me } \\
\text { that question because he's never seen anything about me to prompt that. But irregardless... They should ask the question, } \\
\text { they should ask and be concerned-'Have you ever been confronted with a violent situation?' So that they know, } \\
\text { because... I have seen violent incidents happen right outside my home. I have seen someone get murdered outside my } \\
\text { home, and... not really talking to anybody other than family and a few folks about it." (FG1) }\end{array}$ \\
\hline Misdirected response & $\begin{array}{l}\text { "Every time I go to the doctor, it's always about my weight. I go over here [to the clinic] and there are four doctors there. All of } \\
\text { them focus on me being overweight... overweight ain't the only way you can die. I can go outside and get shot. And I told } \\
\text { them this... [not addressing violence] causes you to be stuck in a box, which causes us to be stuck in a box. Because you } \\
\text { cannot address [my weight] like you really want to." (FG5) }\end{array}$ \\
\hline $\begin{array}{l}\text { Disconnected } \\
\text { response }\end{array}$ & $\begin{array}{l}\text { "When you come to this little nest egg [clinic in upscale neighborhood], and they tell you, 'Think about this.' Then you go } \\
\text { back into your community where everything is just blowing up. And then they say, 'Well did you try this and that?'... My } \\
\text { thinking is, if you are living in [an upscale neighborhood] and you are driving your Mercedes Benz, and then you are going } \\
\text { to ask someone who can barely get } \$ 2.25 \text { to get on the bus to come talk to you... it's just, you are bringing two different } \\
\text { worlds together... I do not think you understand what I am going through. I know you got all the degrees, but still I am } \\
\text { living over here... you need to hire people who understand different communities." (FG4) }\end{array}$ \\
\hline Ineffective response & $\begin{array}{l}\text { Safe resources: "If [doctors] just had a list of where we could go, and [what we could do]... anything for seniors that we'll feel } \\
\text { safe going to." (FG3) } \\
\text { Mental health resources: "Clearly, counseling will help... On the health side, counseling people about the effects of violence. } \\
\text { And then once you get past that, [patients can better] deal with violence in the community and things like that." (FG1) } \\
\text { Spiritual health resources: "I went in with medical issues, and the doctor addressed my experience [of violence]. And this is } \\
\text { just my opinion, but mostly... the answer is a spiritual connection." (FG6) }\end{array}$ \\
\hline
\end{tabular}

I say to myself, I already know the neighborhood don't have no resources. We don't have it. There's nothing there... we didn't have grocery stores for a long time, ever since they burned one down with the riot or whatever. (FG3)

One participant noted a relationship between the unequal distribution of resources and health:

I feel the resources aren't evenly distributed into areas that are having the most violence. And I think that would help people overall, because in the long run, when you neglect neighborhoods and people get chronic illnesses, it costs society more money to treat those chronic illnesses. (FG4)

However, even when resources were available in the neighborhood, many described violence as a physical barrier to accessing them:

I leave my house... you can tell, they're hanging out... kids hang out in front of the store... You have to fight your way to get in the store, and fight your way to get out of the store. (FG6)

If you're fighting a condition, and you own a cane or something, now you have to walk around these guys to get to the store, or you've got to concentrate to get past [them]. (FG2)

Many described local parks as problematic and expressed the need for safe, indoor spaces for exercise:

There's a park by me... I would have to walk from [street name] over to [street name] to get in there. I'm scared to do that. We need a place to go inside. We don't need to be out in no park, doing [exercise]. (FG3)

\section{“Doctors Should Ask:" Inadequate Healthcare Responses to}

Violence. Importantly, participants described various challenges to communicating about violence with their healthcare providers. This theme, unique from previous themes, enumerated several types of healthcare responses experienced by patients, categorized in Table 3. Overall, participants agreed that providers should ask about exposure to community violence and its impact on health, but very few reported ever having these types of conversations (Table 3, "insufficient response"):

I believe personally, if I was a doctor, especially with everything going on now, I would be asking-especially if they know we've got high blood pressure and stuff_- "How have you been doing since this [shooting] has been going on out here today?" I don't know. I just think if you don't ask, you ain't going to know. (FG3)

For some, the focus of clinical care was often misdirected, and addressing community violence could reveal the root cause of illness (Table 3, "misdirected response"). Some expressed concern that healthcare providers do not ask because they are disconnected from their patients' circumstances and experiences (Table 3, "disconnected response"). Thus, engaging patients about community violence was an important way to understand patient context:

[Community violence] is something I never even heard my doctor address. They never talk about that... do they even have a clear view of what we are going 
through? They come [here] and work, and then they go home. (FG4)

Finally, some wanted providers to ask, but also wanted practical information about supportive resources. For these participants, a discussion about community violence was only effective if providers could also address safety concerns (e.g., referrals to indoor gyms) and integrate mental and spiritual health resources into routine care (Table 3, "ineffective response").

\section{DISCUSSION}

Community violence continues to have a pervasive impact on many urban communities and poses unique challenges for adults with chronic conditions. Our findings reveal a number of complex pathways influencing healthy behavior and chronic disease management in high-crime neighborhoods. In our sample of predominantly racial and ethnic minority patients with high rates of obesity and hypertension, we identified eight major themes: (1) perceived risk of being targeted, (2) chronic stress and worry, (3) hypervigilance, (4) social breakdown, (5) chronic isolation, (6) constrained choice, (7) limited access to material resources, and (8) inadequate healthcare responses.

Based on the results of this study, we synthesized a theoretical model to describe potential pathways linking exposure to community violence with poor chronic disease status and outcomes (Fig. 1). First, we found that many older adults and adults with chronic conditions believed they were at higher risk for violence. These perceptions of risk were provoked or exacerbated by either direct exposures to violence or more frequent indirect exposures, although substantial overlap existed in our sample. Fear, an instinctual process, led to downstream cognitive responses that affected even basic daily activities, such as grocery shopping or visiting friends. Implications for older and geriatric populations may be especially salient, as these populations often have higher healthcare needs and already experience greater difficulty with routine daily activities. Many participants described a chronic state of stress or worry, such as staying up at night or worrying about the safety of family members. Related to chronic stress, participants experienced hypervigilance - a state of heightened awareness, intended to detect and address potential threats in the external environment. ${ }^{23}$ Hypervigilance took on internalized forms (e.g., scanning for danger) and externalized forms (e.g., carrying weapons).

Cognitive responses to fear were compounded by a number of behavioral and social responses-notably, constrained choice, chronic isolation, and social breakdown (Fig. 1). Participants described constraints on their daily health choices due to violence, emphasizing limitations on behavior due to location (e.g., avoiding the "street corner") and time (e.g., limiting activities after dark). These constraints sometimes culminated in staying at home, which was experienced as both a physical and social phenomenon. The image that often emerged was that of an older adult aging alone and in poverty, corroborating what Eric Klinenberg has described as the critical determinant of death and vulnerability in aging

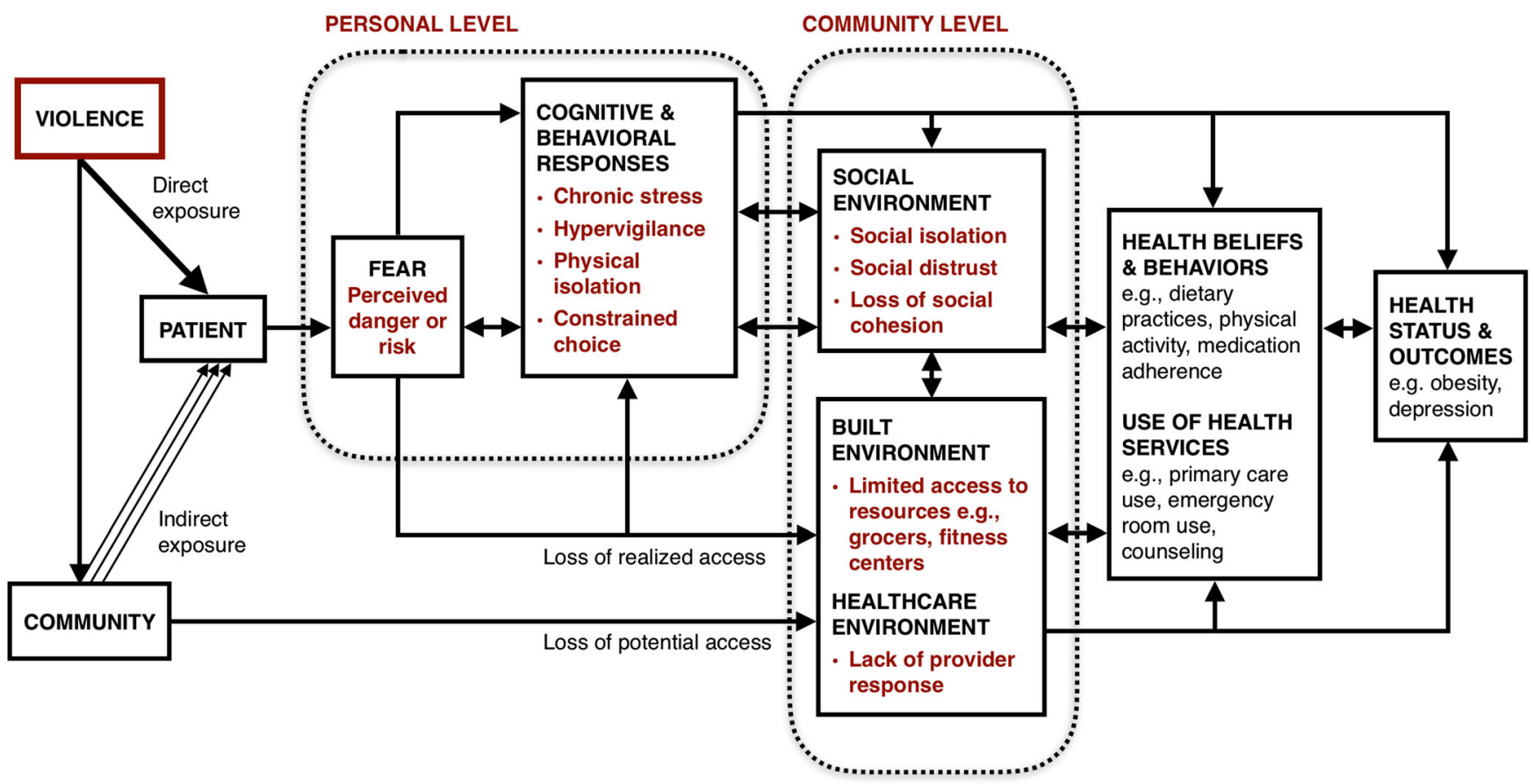

Figure 1 Personal and community responses to violence in adults with chronic conditions. 
populations. $^{24,25}$ Indeed, chronic isolation is one of the few social risk factors that can predict mortality commensurate to traditional clinical risk factors. ${ }^{26}$ However, prior studies have seldom linked these processes to the impacts of violence on more complex health outcomes and behaviors. ${ }^{14}$ Future studies, using methodologies such as social network or geospatial analysis, have tremendous potential to further elucidate the mechanisms between community violence, social isolation, and poor health outcomes.

Participants reported that community violence also had downstream effects on the built environment (Fig. 1). Community violence impacted residents' access to built environment resources in two ways: (1) potential access, the availability of resources in a neighborhood, and (2) realized access, the actual use of resources in a neighborhood. ${ }^{27}$ Several participants noted the maldistribution of resources in neighborhoods with violent crime. Others described violence as a physical barrier to accessing resources that would enable them to pursue a healthy lifestyle (e.g., grocers).

A unique theme that emerged was the role of healthcare in addressing community violence in clinical settings (Fig. 1). The majority of participants had never discussed community violence with any healthcare provider, much less the effects of violence on their health. Failing to engage patients about these experiences may propagate adverse behaviors and heighten concerns that providers are disconnected from their patients' experiences and contexts. Instead, prioritizing concerns about community violence may help providers identify common challenges that are potentially intervenable (e.g., daytime appointments, mail-order prescriptions, referrals to safe resources). ${ }^{28}$ Identifying such challenges will also be critical for working with public health and social service agencies to advance collective efforts, for instance, in the navigation of community-based resources, improving community resource infrastructure, and addressing social needs in affected communities.

There are several limitations to this study. First, participants were recruited from high-crime neighborhoods in Chicago and findings may not be widely generalizable. Similarly, we calculated rates of violent exposures in the sample population, which are not representative of Chicago overall. Although we planned to conduct more patient interviews, participants preferred the focus group format, as it functioned to provide ancillary social support. We therefore prioritized the focus group format for its potential benefits to the sample population.

Recent media attention has galvanized a more concerted effort to curb violence in some of the most disadvantaged and segregated communities in America ${ }^{29}$; however, few efforts have included strategies to address the broader health effects of violence as part of a more comprehensive intervention effort. In fact, those with chronic conditions generally consist of older patient populations, ${ }^{30}$ often excluded from the violence prevention and intervention programs routinely aimed at youth. Older populations may be especially vulnerable to distress related to community violence, with compounding effects for those who are the most sick and poor. We have described some potential health consequences of community violence among adults with chronic conditions. Emergent themes reflect practical targets for an informed healthcare response and conclude with a simple proposition: that healthcare providers should be concerned.

\section{CONCLUSIONS}

Community violence may be a salient social determinant of health in many US urban settings, with particularly detrimental impacts for older adults with chronic conditions. As we consider clinical and public health strategies to address this issue, it is imperative that we advance simultaneous efforts to cure violence and curb its health consequences on the nation's most vulnerable populations.

Acknowledgements: Dr. Tung was supported by the Patient Centered Outcomes Research Institutional Mentored Career Development Program from the Agency for Healthcare Research and Quality (5K12 HS023007). She was also the recipient of a pilot award from the Chicago Center for Diabetes Translation Research supported by the National Institute of Diabetes and Digestive and Kidney Diseases (P30 DK092949). Dr. Peek was supported by the Chicago Center for Diabetes Translation Research (P3O DK092949), the Alliance to Reduce Disparities in Diabetes of the Merck Foundation, and the Greenwall Foundation Faculty Scholars Program. The content is solely the responsibility of the authors and does not necessarily represent the official views of the National Institutes of Health.

Corresponding Author: Elizabeth L. Tung, MD, MS; Section of General Internal Medicine, Department of Medicine, Chicago Center for Diabetes Translation Research University of Chicago, Chicago, IL, USA (e-mail: eliztung@uchicago.edu).

Author Contributions Respective author contributions are as follows. Study concept and design: E.L.T. and M.E.P. Acquisition of data: all authors. Analysis and interpretation of data: all authors. Drafting of the manuscript: E.L.T. and M.E.P. Critical revision of the manuscript for important intellectual content: all authors. Administrative, technical, or material support: M.E.P. Supervision: M.E.P. Final approval of the version to be published: all authors.

\section{Compliance with Ethical Standards:}

Conflict of Interest: The authors declare that they do not have a conflict of interest.

\section{REFERENCES}

1. Centers for Disease Control and Prevention. Web-based Injury Statistics Query and Reporting System. 2015.

2. Voisin DR. The public health implications of violence exposures: violence and immunological factors among perinatally HIV-infected youth. J Adolesc Health. 2016;59:3-4.

3. Voisin DR, Neilands TB. Community violence and health risk factors among adolescents on Chicago's southside: does gender matter? J Adolesc Health. 2010;46:600-2.

4. Reese C, Pederson T, Avila S, Joseph K, Nagy K, Dennis A, Wiley D, Starr F, Bokhari F. Screening for traumatic stress among survivors of urban trauma. J Trauma Acute Care Surg. 2012;73:462-7; discussion 467-8.

5. Lovasi GS, Hutson MA, Guerra M, Neckerman KM. Built environments and obesity in disadvantaged populations. Epidemiol Rev. 2009;31:7-20. 
6. Fish JS, Ettner S, Ang A, Brown AF. Association of perceived neighborhood safety with [corrected] body mass index. Am J Public Health. 2010;100:2296-303.

7. Yu E, Lippert AM. Neighborhood crime rate, weight-related behaviors, and obesity: a systematic review of the literature. Sociol Compass. 2016;10:187-207.

8. Doyle S, Kelly-Schwartz A, Schlossberg M, Stockard J. Active community environments and health: the relationship of walkable and safe communities to individual health. J Am Plan Assoc. 2006;72:19-31.

9. Sundquist $\mathbf{K}$, Theobald $\mathbf{H}$, Yang $\mathbf{M}, \mathbf{L i} \mathbf{X}$, Johansson SE, Sundquist $\mathbf{J}$. Neighborhood violent crime and unemployment increase the risk of coronary heart disease: a multilevel study in an urban setting. Soc Sci Med. 2006;62:2061-71.

10. Foster S, Giles-Corti B. The built environment, neighborhood crime and constrained physical activity: an exploration of inconsistent findings. Prev Med. 2008;47:241-51

11. Billimek J, Sorkin DH. Self-reported neighborhood safety and nonadherence to treatment regimens among patients with type 2 diabetes. $J$ Gen Intern Med. 2012;27:292-6.

12. McEwen B, Lasley EN. Allostatic load: when protection gives way to damage. Adv Mind-Body Med. 2003;19:28-33.

13. Astell-Burt T, Feng $\mathbf{X}$, Kolt GS, Jalaludin B. Does rising crime lead to increasing distress? Longitudinal analysis of a natural experiment with dynamic objective neighbourhood measures. Soc Sci Med. 2015;138:6873.

14. Lorenc T, Clayton S, Neary D, Whitehead M, Petticrew M, Thomson H, Cummins S, Sowden A, Renton A. Crime, fear of crime, environment, and mental health and wellbeing: mapping review of theories and causal pathways. Health Place. 2012;18:757-65.

15. Bogar S, Beyer KM. Green space, violence, and crime: a systematic review. Trauma Violence Abuse. 2016;17:160-71.

16. Sampson RJ, Raudenbush Sw, Earls F. Neighborhoods and violent crime: a multilevel study of collective efficacy. Science (New York, NY). 1997;277:918-24.

17. Ruijsbroek A, Droomers M, Groenewegen PP, Hardyns W, Stronks K. Social safety, self-rated general health and physical activity: changes in area crime, area safety feelings and the role of social cohesion. Health Place. 2015;31:39-45.

18. Mmari $\mathbf{K}$, Lantos $\mathbf{H}$, Brahmbhatt $\mathbf{H}$, Delany-Moretlwe S, Lou C, Acharya R, Sangowawa A. How adolescents perceive their communities: a qualitative study that explores the relationship between health and the physical environment. BMC Public Health. 2014; 14:349.

19. U.S. Department of Veterans Affairs National Center for PTSD. Brief Trauma Questionnaire (BTQ).

20. Payne TJ, Wyatt SB, Mosley TH, Dubbert PM, Guiterrez-Mohammed ML, Calvin RL, Taylor HA Jr, Williams DR. Sociocultural methods in the Jackson Heart Study: conceptual and descriptive overview. Ethn Dis. 2005; 15:S6-38-48.

21. Centers for Disease Control and Prevention. Behavioral Risk Factor Surveillance System Survey Questionnaire. 2012.

22. Lindau ST. South Side Population Health Study. 2013;10.

23. Kimble M, Boxwala M, Bean W, Maletsky K, Halper J, Spollen K, Fleming $\mathbf{K}$. The impact of hypervigilance: evidence for a forward feedback loop. J Anxiety Disord. 2014;28:241-5.

24. Klinenberg E. Heat Wave: A Social Autopsy of Disaster in Chicago. Chicago, IL: University of Chicago Press; 2002.

25. Klinenberg E. Social isolation, loneliness, and living alone: identifying the risks for public health. Am J Public Health. 2016;106:786-7.

26. Pantell M, Rehkopf D, Jutte D, Syme SL, Balmes J, Adler N. Social isolation: a predictor of mortality comparable to traditional clinical risk factors. Am J Public Health. 2013;103:2056-62.

27. Andersen RM. Revisiting the behavioral model and access to medical care: does it matter? J Health Soc Behav. 1995;36: 1-10.

28. Tung EL, Peek ME. Linking community resources in diabetes care: a role for technology? Curr Diab Rep. 2015; 15:45.

29. Bauchner H, Rivara FP, Bonow RO, Bressler NM, Disis ML, Heckers S, Josephson SA, Kibbe MR, Piccirillo JF, Redberg RF, Rhee JS, Robinson JK. Death by gun violence-a public health crisis. JAMA Intern Med. 2017.

30. Fox S, Duggan M, Rainie L, Purcell $\mathbf{K}$. The diagnosis difference: a portrait of the $45 \%$ of U.S. adults living with chronic health conditions. $2013 ; 94$. 